\title{
CORDEL COMO RECURSO JORNALÍSTICO NO SÉCULO XXI
}

\section{Giovana Leandra Silva Loureiro' \\ Vânia Braz de Oliveira² \\ Paulo Roxo Barja ${ }^{3}$}

Resumo: O presente trabalho busca apresentar o histórico do cordel brasileiro como veículo informacional, enfatizando a relação da literatura popular de cordel com o jornalismo literário na contemporaneidade. Objetiva-se também evidenciar as perspectivas jornalísticas que discorreram por este meio. Utilizamos para a produção deste artigo as pesquisas bibliográfico-documentais; em seguida, selecionamos uma reportagem e a estruturamos seguindo a regras de um cordel. A discussão descreve fontes de informação e avalia o papel da literatura cordelista neste processo. Conclui-se, a partir da produção de uma narrativa factual em cordel, que a comunicação de fatos pode transcender os modelos tradicionais do jornalismo, permitindo, através de um diálogo com a realidade e as expressões culturais a compreensão dos fatos pelo interlocutor.

Palavras-chave: Comunicação; Cordel; Jornalismo literário; Literatura popular; Notícia.

\footnotetext{
${ }^{1}$ LabCom/FCSAC/Universidade do Vale do Paraíba, Brasil. E-mail: giovana_loureiro@hotmail.com.

2 LabCom/FCSAC/Universidade do Vale do Paraíba, Brasil. E-mail: vaniajor@univap.br.

${ }^{3}$ LabCom/FCSAC/Universidade do Vale do Paraíba, Brasil. E-mail: barja@univap.br.
} 